\title{
Glia Contribute to the Purinergic Modulation of Inspiratory Rhythm-Generating Networks
}

\author{
Adrianne G. Huxtable, ${ }^{1,2 *}$ Jennifer D. Zwicker, ${ }^{1,2 *}$ Tucaauê S. Alvares, ${ }^{1,2}$ Araya Ruangkittisakul, ${ }^{1,2}$ Xin Fang, ${ }^{1,2}$ \\ Leanne B. Hahn, ${ }^{1,2}$ Elena Posse de Chaves, ${ }^{4}$ Glen B. Baker, ${ }^{5}$ Klaus Ballanyi, ${ }^{1,2}$ and Gregory D. Funk ${ }^{1,2,3}$ \\ Departments of ${ }^{1}$ Physiology and ${ }^{2}$ Pediatrics, Faculty of Medicine and Dentistry, University of Alberta, Edmonton, Alberta T6G 2H7, Canada, ${ }^{3}$ Department \\ of Physiology, Faculty of Medicine and Health Science, University of Auckland, Private Bag 92019, Auckland, New Zealand, ${ }^{4}$ Department of Pharmacology, \\ Faculty of Medicine and Dentistry, University of Alberta, Edmonton, Alberta T6G 2H7, Canada, and ${ }^{5}$ Neurochemical Research Unit, Department of \\ Psychiatry, Faculty of Medicine and Dentistry, University of Alberta, Edmonton, Alberta T6G 2G3, Canada
}

Glia modulate neuronal activity by releasing transmitters in a process called gliotransmission. The role of this process in controlling the activity of neuronal networks underlying motor behavior is unknown. ATP features prominently in gliotransmission; it also contributes to the homeostatic ventilatory response evoked by low oxygen through mechanisms that likely include excitation of preBötzinger complex (preBötC) neural networks, brainstem centers critical for breathing. We therefore inhibited glial function in rhythmically active inspiratory networks in vitro to determine whether glia contribute to preBötC ATP sensitivity. Glial toxins markedly reduced preBötC responses to ATP, but not other modulators. Furthermore, since preBötC glia responded to ATP with increased intracellular $\mathrm{Ca}^{2+}$ and glutamate release, we conclude that glia contribute to the ATP sensitivity of preBötC networks, and possibly the hypoxic ventilatory response. Data reveal a role for glia in signal processing within brainstem motor networks that may be relevant to similar networks throughout the neuraxis.

\section{Introduction}

Traditionally, glia have been recognized for their important roles in metabolically supporting neurons (Tsacopoulos, 2002), indirectly influencing neuronal activity by buffering extracellular $\mathrm{K}^{+}$ (Gardner-Medwin et al., 1981), and removing neurotransmitters from the extracellular space (Parpura et al., 1994). It is now clear that glia express receptors for a variety of neurotransmitters (including glutamate, GABA, norepinephrine, and acetylcholine), release a number of gliotransmitters (including glutamate, ATP, and D-serine), and directly modulate neuronal activity through gliotransmission (Haydon and Carmignoto, 2006; He and Sun, 2007). Despite growing evidence that gliotransmission modulates neuronal activity and the recent demonstration in mice that gliotransmission is important for sleep homeostasis (Halassa et al., 2009), understanding its role in controlling the activity of neural networks underlying complex behaviors is limited.

To further explore the role of glia in modulating network behavior, we examined a brainstem network that generates breathing (Feldman and Del Negro, 2006), a vital rhythmic mo-

\footnotetext{
Received Dec. 5, 2009; revised Jan. 14, 2010; accepted Jan. 24, 2010.

This work was supported by the Alberta Heritage Foundation for Medical Research (AHFMR), Canadian Institute for Health Research (CIHR), Canadian Foundation for Innovation, and the Alberta Science and Research Authority. A.G.H. was supported by a Natural Sciences and Engineering Research Council of Canada Postgraduate Doctoral Scholarship and the CIHR Strategic Training Program in Maternal-Fetal-Newborn Health; G.D.F., K.B., and G.B. are AHFMR Scientists. We thank Gail Rauw for expert technical assistance with the HPLC experiments.

${ }^{*}$ A.G.H. and J.D.Z. contributed equally to this work.

Correspondence should be addressed to Adrianne G. Huxtable at her present address: Department of Comparative Biosciences, University of Wisconsin-Madison, 2015 Linden Drive, Madison, WI 53705. E-mail: ahuxtable@wisc.edu or huxtable@ualberta.ca.

DOI:10.1523/JNEUROSCI.6027-09.2010

Copyright $\odot 2010$ the authors $\quad 0270-6474 / 10 / 303947-12 \$ 15.00 / 0$
}

tor behavior that controls homeostasis, to understand the involvement of glia in the modulation of this behavior by ATP. ATP acts by binding to seven subtypes of ionotropic $\mathrm{P} 2 \mathrm{X}$ receptors (P2X ${ }_{1-7}$ Rs) (North, 2002) and eight subtypes of metabotropic P2YRs (P2Y $1,2,4,6,11-14$ ) (Abbracchio et al., 2003). Seminal studies (Edwards et al., 1992; Evans et al., 1992; Silinsky et al., 1992) that established ATP as a neurotransmitter contributing to fast synaptic transmission in the CNS are now supported by extensive literature showing multiple presynaptic and postsynaptic actions of P2XRs and P2YRs on neuronal excitability (Gourine, 2005; Gourine et al., 2005; Lorier et al., 2007). ATP is also a gliotransmitter that modulates synaptic efficacy on multiple time scales at glutamatergic synapses (Zhang et al., 2003; Gordon et al., 2005), inhibits and excites neurons (Newman, 2003; Burnstock, 2007), and stimulates hormone release from hypothalamic neurons (Espallergues et al., 2007). In addition to releasing ATP, glia express multiple P2R subtypes that when activated can initiate selfpropagating calcium waves that are proposed to influence local network excitability (Fiacco and McCarthy, 2006).

Within respiratory networks, ATP and P2R signaling contribute to homeostatic ventilatory responses (Gourine et al., 2003, 2005). During hypoxia, for example, a delayed release of ATP from respiratory regions of the medulla activates P2Rs and attenuates the secondary hypoxic ventilatory depression (Gourine et al., 2005), which can be life threatening in premature/newborn infants. This excitation is likely to involve a potent $\mathrm{P}_{2} \mathrm{Y}_{1} \mathrm{R}-$ mediated excitation of the preBötzinger complex (preBötC) (Lorier et al., 2007), the proposed site of inspiratory rhythm generation (Smith et al., 1991). The cellular mediators of this ATPevoked excitation are not known. The majority of neurons in the 
preBötC are weakly excited by ATP (Lorier et al., 2008) and likely contribute to the frequency response; however, based on the emerging role of glia in ATP signaling (Newman, 2003; Zhang et al., 2003; Gordon et al., 2005; Burnstock, 2007; Espallergues et al., 2007), the aim of this study is to test the hypothesis that glia are important contributors to the modulatory actions of ATP on preBötC inspiratory rhythm generating networks. These data will provide insight into the general roles of glia and ATP in modulating the activity of neural networks involved in generating rhythmic motor behaviors.

\section{Materials and Methods}

All experiments were conducted in accordance with the guidelines of the Canadian Council on Animal Care and were approved by the University of Alberta Animal Ethics Committee.

\section{Electrophysiology}

Rhythmic, transverse, $700-\mu \mathrm{m}$-thick slices of the medulla from Sprague Dawley rats [postnatal day $0-4(\mathrm{P} 0-\mathrm{P} 4)]$ were cut with the preBötC at the rostral surface of the slice $(-0.35 \mathrm{~mm}$ caudal to the caudal aspect of the facial nucleus) (Smith et al., 1991; Ruangkittisakul et al., 2006; Lorier et al., 2007). Slices were perfused $\left(8 \mathrm{ml} / \mathrm{min}, 28^{\circ} \mathrm{C}\right)$ with artificial CSF (aCSF) containing the following (in $\mathrm{mM}$ ): $120 \mathrm{NaCl}, 3 \mathrm{KCl}, 1.0 \mathrm{CaCl}_{2}, 2.0$ $\mathrm{MgSO}_{4}, 26 \mathrm{NaHCO}_{3}, 1.25 \mathrm{NaH}_{2} \mathrm{PO}_{4}$, and 20 D-glucose, and equilibrated with $95 \% \mathrm{O}_{2} / 5 \% \mathrm{CO}_{2}$ to $\mathrm{pH} 7.45$. Rhythmic inspiratory-related motor output was recorded through suction electrodes placed on the hypoglossal (XII) nerve rootlets and the site on the rostral surface overlying the preBötC that generated the largest amplitude rhythmic signal. Signals were amplified, filtered ( $300 \mathrm{~Hz}$ to $1 \mathrm{kHz}$ ), rectified, and integrated. Data were acquired using Axoscope 9.2 and a Digidata 1322 A/D (Molecular Devices).

Drugs and their application. ATP (0.1 mM, P2R agonist), fluoroacetate (FA, $5 \mathrm{~mm}$, glial aconitase enzyme inhibitor), methionine sulfoximine (MSO, $0.1 \mathrm{~mm}$, glial glutamine synthetase enzyme inhibitor), glutamine (GLN, $1.5 \mathrm{~mm}$ ), 4-(2-butyl-6,7-dichloro-2-cyclopentylindan-1-on-5yl)oxybutyric acid (DCPIB, $0.02 \mathrm{~mm}$, volume-regulated anion channels inhibitor), tetrodotoxin (TTX, $0.5 \mu \mathrm{M}$ ), 6-cyano-7-nitroquinoxaline2,3-dione (CNQX, $0.1 \mathrm{~mm}$ ), DL-2-amino-5-phosphonopentanoic acid (APV, $0.05 \mathrm{~mm})$, glutamate $(1 \mathrm{~mm})$, suramin $(0.5 \mathrm{~mm})$, and pyridoxal phosphate-6-azo(benzene-2,4-disulfonic acid) tetrasodium salt (PPADS $0.1 \mathrm{mM})$ were obtained from Sigma-Aldrich. Substance-P (SP, $1 \mu \mathrm{M})$, MRS 2365 (0.001 mM, P2 ${ }_{1} \mathrm{R}$ agonist, and MRS 2279 (0.5 mM, P2 ${ }_{1} \mathrm{R}$ antagonist) were obtained from Tocris Bioscience. Drugs were prepared as stock solutions in aCSF and frozen in aliquots. ATP was made fresh each day.

Drugs were bath applied (FA, MSO, GLN, and DCPIB) and given 15 min to equilibrate, or were microinjected (ATP and SP) using triplebarreled glass micropipettes (5-6 $\mu \mathrm{m}$ outer diameter per barrel) lowered into the preBötC with a micromanipulator. Injections were made with a controlled pressure source into the site where ATP $(0.1 \mathrm{~mm}, 10 \mathrm{~s})$ produced the maximum frequency increase, which was previously established to be the preBötC (Lorier et al., 2007). Consecutive agonist applications were at $15 \mathrm{~min}$ intervals.

Whole-cell recording. For whole-cell recording of inspiratory neurons, $700 \mu \mathrm{m}$ rhythmic medullary slice preparations were used as described above. For whole-cell recording of glia, brainstems were sectioned to the vicinity of the preBötC, and three $300 \mu \mathrm{m}$ sections were taken, but were not checked for rhythmicity. Sections were then visually inspected, and those corresponding to the preBötC (1-2 per animal) were used for recording. It is therefore possible that some cells were located just rostral or caudal to the preBötC. Cells located near the surface were visualized in an $800 \mu \mathrm{l}$ chamber $\left(27^{\circ} \mathrm{C}\right.$, flow rate of $\left.2 \mathrm{ml} / \mathrm{min}\right)$ with differential interference contrast and infrared video microscopy. Glass micropipettes (3.5-4.5 $\mathrm{M} \Omega$ ) were filled with solution containing the following (in $\mathrm{mM}$ ): 140 potassium-gluconate, $5 \mathrm{NaCl}, 1 \mathrm{CaCl}_{2}, 1 \mathrm{MgCl}_{2}, 10$ EGTA, 10 HEPES, and 1 glucose. $\mathrm{pH}$ was adjusted to $7.25-7.30$ by $5 \mathrm{~m} \mathrm{KOH}$. Glia were targeted based on published anatomical features (Grass et al., 2004), such as being half the diameter of neurons in the region $(\sim 10 \mu \mathrm{m})$, ovoid, with small processes, and close to blood vessels. Glia were distinguished from neurons electrophysiologically under current clamp by delivering an incrementing series of rectangular current steps (8 steps, $1 \mathrm{~s}$ ) from a holding potential of $-60 \mathrm{mV}$ until the cell fired action potentials or membrane potential was depolarized above $-10 \mathrm{mV}$. Cells that did not fire action potentials (presumptive glia) were tested for agonist sensitivity under voltage-clamp conditions at a holding potential of -60 $\mathrm{mV}$ by microinjecting drugs from triple-barreled glass micropipettes (as above) placed $5-10 \mu \mathrm{m}$ above the slice surface. Negative voltage pulses $(-3$ to $-30 \mathrm{mV}, 0.5 \mathrm{~s}$ duration, $0.5 \mathrm{~Hz})$ or ramps $(-80$ to $-30 \mathrm{mV}$ over $2 \mathrm{~s}$ during control, drug, or washout) were applied to monitor input resistance $\left(R_{\mathrm{N}}\right)$. Membrane current or voltage signals, obtained using a Multiclamp 700Aa amplifier (Molecular Devices), were low-pass filtered (Bessel $5 \mathrm{kHz}$ ), acquired, and controlled using Digidata 1322A A/D board with Axoscope 9.2 and Clampex 9.2 (pClamp, Molecular Devices). Liquid junction potentials for potassium-gluconate solution $(13 \mathrm{mV})$ were corrected off-line.

$\mathrm{Ca}^{2+}$ imaging of preBötC cells in rhythmic medullary slices Rhythmic, $700 \mu \mathrm{m}$ slices were placed in a recording chamber $(1.5 \mathrm{ml})$, perfused with aCSF $(5 \mathrm{ml} / \mathrm{min})$ and rhythm monitored from the XII nerve rootlets. Fluo-4-AM (0.5 mM, Sigma-Aldrich) was pressure injected (0.7-1 psi) into the preBötC for 10 min using a single barrel pipette (5-10 $\mu \mathrm{m})$ (Ruangkittisakul and Ballanyi, 2006; Ruangkittisakul et al., 2006, 2008). Fluorescence signals evoked by bath-applied agonists/antagonists were monitored through a multiphoton confocal microscope (Olympus FV300, Fluoview software; Carsen Group) connected to a Ti:Sa laser (Coherent) using a $20 \times$ objective and $3 \times$ digital zoom with scan rates of $1.08 \mathrm{~s} /$ frame. ATP was bath applied in the majority of experiments by pumping $0.1 \mathrm{~mm}$ ATP through the chamber at a flow rate of $5 \mathrm{ml} / \mathrm{min}$ and monitoring the time course of fluorescence changes. Other bath-applied drugs, including TTX $(0.5 \mu \mathrm{M})$ to block action potentials and CNQX $(10 \mu \mathrm{M})$ and APV $(50 \mu \mathrm{M})$ to block AMPA and NMDA receptors, respectively, were added to the perfusion solution and were allowed to equilibrate for $15 \mathrm{~min}$ before the application of ATP. ATP $(0.1$ $\mathrm{mm}, 30 \mathrm{~s}$ ) was also applied locally in some experiments using methods described for slices above. Consecutive ATP applications were separated by $15 \mathrm{~min}$. While it is typical that the concentration of drug must be $\sim 10$-fold higher during local than during bath application to produce the same effect, this is not the case with ATP. Bath-applied ATP has poor access to the preBötC, because it is degraded by ectonucleotidases (Funk et al., 2008). This is supported by our demonstration with ATP biosensors, where to obtain concentrations of $10 \mu \mathrm{M}$ ATP below the slice surface, the bath concentration must be raised 100-fold to $1 \mathrm{~mm}$ (Funk et al., 2008). Also, ATP diffuses small distances in tissue due to an active process that we attribute to enzymatic breakdown (Huxtable et al., 2009). Second, with bath application, drug concentration rises slowly and can lead to receptor desensitization/internalization, which will greatly attenuate responses.

\section{Primary cultures of glia from the ventral medulla at the level of the preBötC}

Culture preparation. Two types of cultures were prepared from $300 \mu \mathrm{m}$ preBötC slices. First, the slice was cut into dorsal and ventral halves at the dorsal border of nucleus ambiguus. Midline structures were removed and the ventral quadrants were collected for ventral medulla cultures. Second, the preBötC region was collected using 21 ga tissue punches to produce preBötC cultures. All culture media were used at $37^{\circ} \mathrm{C}$. Both types of tissues were transferred to separate $15 \mathrm{ml}$ conical tubes, washed $(2 \times)$ with Dulbecco's PBS $(2 \mathrm{ml})$ (Invitrogen), and centrifuged $(1500 \times$ $g, 1 \mathrm{~min})$. Ventral tissue was then incubated in digestion buffer $(0.25 \%$ trypsin-EDTA in PBS; Invitrogen) for $5 \mathrm{~min}$. The supernatant was replaced with BME-glucose solution $(2 \mathrm{ml})$ that was produced by adding to $1 \times$ basal medium Eagle solution (BME; Invitrogen): $3.3 \mathrm{~mm}$ glucose (final concentration of $8.8 \mathrm{~m}$ ), 2 mM L-GLN (Sigma-Aldrich), penicillin/ streptomycin (10,000 U of penicillin/10,000 $\mu \mathrm{g}$ of streptomycin per $\mathrm{ml}$; Invitrogen), and $10 \%$ rat serum (RS). The tissue was centrifuged $(1500 \times$ $\mathrm{g}$, $3 \mathrm{~min})$, the supernatant replaced with BME-glucose $(1 \mathrm{ml})$, and tissue homogenized through trituration and centrifuged with fresh BME- 
glucose at $1500 \times \mathrm{g}$ for $6 \mathrm{~min}$ and $3 \mathrm{~min}$. Tissue was then resuspended in BME-glucose and cells were plated on T25 flasks (Flask TC Vent $25 \mathrm{~cm}$, Fisher Scientific). In contrast, preBötC punches were plated directly on Thermanox plastic coverslips (NUNC Brand products) and placed in a T25 flask containing BME-glucose $(1 \mathrm{ml})$.

Ventral medullary cells and preBötC coverslips were incubated in $1 \mathrm{ml}$ of BME-glucose for the first $24 \mathrm{~h}$ and $1 \mathrm{ml}$ of BME-sorbitol (10\% RS) thereafter. BME-sorbitol was equivalent to BME-glucose except that D-glucose was replaced with sorbitol ( $2.5 \mathrm{~mm}$, Fisher Scientific) to select for glia. After 48 h, fresh media (with $2.5 \%$ RS) was added and changed every $3 \mathrm{~d}$. Ventral tissue cultures were maintained for 2 weeks and then split, plated on glass coverslips (Electron Microscopy Sciences) and studied (imaging and immunocytochemistry) 3-5 d later. PreBötC punches (on coverslips) were grown for $6 \mathrm{~d}$, smeared, maintained in a 24-well plate for 2 weeks, and then imaged.

$\mathrm{Ca}^{2+}$ imaging of glial cultures. Cultures were loaded for $45 \min \left(35^{\circ} \mathrm{C}\right)$ with the membrane-permeant $\mathrm{Ca}^{2+}$-sensitive dye, fluo-4-AM (0.01 mM) in aCSF, containing the following (in $\mathrm{mM}$ ): $117 \mathrm{NaCl}, 5 \mathrm{KCl}, 1 \mathrm{NaH}_{2} \mathrm{PO}_{4}$, $2 \mathrm{CaCl}_{2}, 1 \mathrm{MgSO}_{4}, 26 \mathrm{NaHCO}_{3}$, and 6 glucose. Coverslips were then moved to the recording chamber $\left(3 \mathrm{ml}\right.$ volume, $28^{\circ} \mathrm{C}, 6 \mathrm{ml} / \mathrm{min}$ flow rate) containing aCSF gassed with $20 \% \mathrm{O}_{2} / 5 \% \mathrm{CO}_{2} / 75 \% \mathrm{~N}_{2}$.

Fluorescence intensity was measured using an upright microscope (Zeiss Axioskop2 FS Plus) fitted with a $40 \times$ water-immersion objective $(\mathrm{NA}=0.8)$, xenon arc lamp $(175 \mathrm{~W}$, Sutter Instruments $)$, and a SensiCam QE (Cooke Corporation). Imaging Workbench 6.0 (INDEC BioSystems) was used to control a Lambda 10-2 shutter system (Sutter Instruments). Images were acquired at $1 \mathrm{~Hz}$ (20 ms exposure). Drugs (ATP, 0.01 mM, MRS 2365, $0.001 \mathrm{~mm}$; MRS 2279, $0.5 \mathrm{~mm}$; suramin, 0.5 mM; PPADS, $0.1 \mathrm{~mm}$ ) were applied from triple-barreled micropipettes using a controlled pressure source. Consecutive agonist applications were 10 min apart. Locally applied ATP concentration was 10 -fold lower in these experiments compared to slice experiments because of improved drug access to glial monolayers.

HPLC. Ventral medulla cultures in 24-well plates were washed with aCSF $(1 \mathrm{ml}, 2 \times)$ and incubated for $1 \mathrm{~min}$ in $250 \mu \mathrm{l}$ of aCSF. A $50 \mu \mathrm{l}$ sample was removed from each well to determine baseline glutamate levels and this was replaced with $50 \mu \mathrm{l}$ of aCSF, ATP, or ATP and a P2 receptor antagonist cocktail. Final concentrations were: $50 \mu \mathrm{M}$ ATP, $500 \mu \mathrm{M}$ MRS 2279, $500 \mu \mathrm{M}$ suramin, and $100 \mu \mathrm{M}$ PPADS. After $5 \mathrm{~min}$, a $250 \mu \mathrm{l}$ sample was collected for HPLC.

Samples were centrifuged $(12,000 \times g, 5 \mathrm{~min})$ and the supernatants analyzed blindly for glutamate by reverse-phase HPLC with fluorimetric detection after reacting with $\mathrm{N}$-isobutyryl-L-cysteine and $o$-phthaldialdehyde (Grant et al., 2006). The fluorescence detector was set at an excitation wavelength of $344 \mathrm{~nm}$ and an emission wavelength of $433 \mathrm{~nm}$. Glutamate levels in the $5 \mathrm{~min}$ samples are reported relative to baseline levels measured at time 0 .

Immunocytochemistry. When cultured cells were resuspended from T25 flasks, some cells were seeded in 24-well culture plates for immunocytochemistry. After $2 \mathrm{~d}$, wells were washed $(3 \times)$ with PBS, pH 7.2, and fixed with $4 \%$ paraformaldehyde in phosphate buffer (PB) for $20 \mathrm{~min}$. Cells were treated with Triton X-100 $(0.1 \%, 15 \mathrm{~min}$ at room temperature), washed with PBS $(2 \times)$, and blocked with $2 \%$ bovine serum albu$\mathrm{min}$ in PBS for $2 \mathrm{~h}$. Cells were then incubated in the primary antibodies in the blocking buffer for $2 \mathrm{~h}$ at room temperature. Primary antibodies included rabbit polyclonal anti-GFAP (1:500, Promega), monoclonal anti-S-100 ( $\beta$-subunit) (1:1000, Sigma-Aldrich), rabbit anti-P2Y (1:500, Alomone Labs), monoclonal antibody anti-neurofilament 160 $\mathrm{kDa}$, clone NN18 (Millipore), and polyclonal rabbit anti-neurofilament $150 \mathrm{kDa}$ (Millipore). Monoclonal anti-S-100 ( $\beta$-subunit) was used in conjunction with either rabbit polyclonal anti-GFAP, rabbit anti-P2 $\mathrm{Y}_{1}$, or polyclonal anti-neurofilament 150. Monoclonal antibody anti-neurofilament 160 was used with rabbit polyclonal anti-GFAP. After three washes with PBS, cells were incubated with the secondary antibodies in the blocking buffer for $1 \mathrm{~h}$ at room temperature. Secondary antibodies used include Alexa Fluor 488 donkey anti-mouse IgG $(\mathrm{H}+\mathrm{L})(1: 1000$, Invitrogen) for the monoclonal anti-S-100 ( $\beta$-subunit) or anti-neurofilament antibodies. Alexa Fluor 594 donkey anti-rabbit IgG $(H+L)(1: 1000$, Invitrogen) was used with the rabbit anti-P2 $\mathrm{Y}_{1}$ primary antibody. Cells were washed with
PBS $(3 \times)$, Hoechst solution (nuclear stain; Sigma-Aldrich) was applied, and mounting medium was added to the wells for imaging on a Nikon Eclipse TE300 fluorescent microscope equipped with a digital camera. Images were adjusted for brightness and contrast using Northern Eclipse Image analysis (Empix Imaging). All images within a series were adjusted identically.

\section{Data and statistical analysis}

Inspiratory frequency, cell holding current, and $R_{\mathrm{N}}$ were analyzed offline using Clampfit 9.2 (pClamp, Molecular Devices). Effects of bathapplied drugs on inspiratory frequency were assessed by comparing instantaneous frequencies [(1/burst period $) \times 60]$ averaged over $5 \mathrm{~min}$ during control and the steady-state drug response. For local drug applications, baseline frequency ( 2 min before drug application) was compared to the maximum frequency observed within the first minute of drug application, as determined from a moving average of three cycles.

For $\mathrm{Ca}^{2+}$ imaging of rhythmic slices, fluo-4-labeled cells were selected as regions of interest (ROIs). The area and fluorescence intensity of each ROI were determined using Fluoview V 5.0. Cells were grouped based on ROI size ( $\left.\leq 50 \mu \mathrm{m}^{2}, 50-100 \mu \mathrm{m}^{2}, \geq 100 \mu \mathrm{m}^{2}\right)$. Raw fluorescence intensity, measured under control conditions and in response to ATP, in the absence and presence of antagonists was compared within and between groups.

$\mathrm{Ca}^{2+}$ imaging data from glial cultures were analyzed offline using Imaging Workbench 6.0 (INDEC BioSystems). ROIs were drawn around cell margins, and baseline fluorescence for each ROI was calculated from the average intensity of three images taken before drug administration. Agonist effects were assessed by comparing the maximum agonistevoked fluorescence value to the baseline fluorescence. Antagonist effects were assessed by comparing, relative to baseline (maximum fluorescence/baseline fluorescence), the maximum fluorescence evoked by the agonist in the absence and presence of the antagonist.

Differences between means were compared using raw data (except data relevant to Fig. $8 C-E$ ) and either a $t$ test or one-way or two-way ANOVA with multiple-comparison post hoc tests (GraphPad Prism Version 4, GraphPad Software). $p<0.05$ was considered significant. Data are expressed as mean \pm SEM.

\section{Results \\ Contribution of glia to the ATP-evoked increase in inspiratory frequency}

The effects of bath-applied glial toxins on network behavior were assessed by monitoring changes in baseline inspiratory frequency generated by medullary slices. As reported previously (Hülsmann et al., 2000), FA ( $5 \mathrm{~mm}, n=10)$ and MSO (0.1 mM, $n=7)$ significantly reduced baseline rhythm from $14.1 \pm 1.0$ to $10.6 \pm$ $1.8 \mathrm{bursts} / \mathrm{min}$ and from $14.8 \pm 2.0$ to $11.8 \pm 2.2 \mathrm{bursts} / \mathrm{min}$ after $30 \mathrm{~min}$, respectively (data not shown, one-way ANOVA, Tukey's multiple-comparison test). Baseline frequency fell further to $8.6 \pm 1.5$ bursts $/ \mathrm{min}$ and $8.9 \pm 2.0$ bursts $/ \mathrm{min}$ after $60 \mathrm{~min}$. After $60-150 \mathrm{~min}$ in FA or MSO, inspiratory activity was reduced by at least $75 \%$ of control in all preparations. In four preparations (two with FA; two with MSO), rhythm stopped completely. At this time, application of GLN $(1.5 \mathrm{~mm})$ in the presence of the toxin returned rhythm to $10.9 \pm 1.1$ bursts/min in FA or $11.6 \pm 1.7$ bursts/min in MSO within $15 \mathrm{~min}$.

To examine the contribution of glia to the effect of P2R activation on inspiratory frequency, we compared, in the same slice, network responses to local application of ATP and SP into the preBötC in control conditions and after restoration of toxindisrupted rhythm with GLN. SP is a neuropeptide that evokes a potent increase in inspiratory frequency when applied into the preBötC (Gray et al., 1999, 2001) and was used as a control to assess the ability of the inspiratory network to respond to excitatory stimuli after toxin treatment. In control conditions, ATP $(0.1 \mathrm{~mm}, 10 \mathrm{~s})$ caused frequency to increase from $14.6 \pm 2.5$ to 

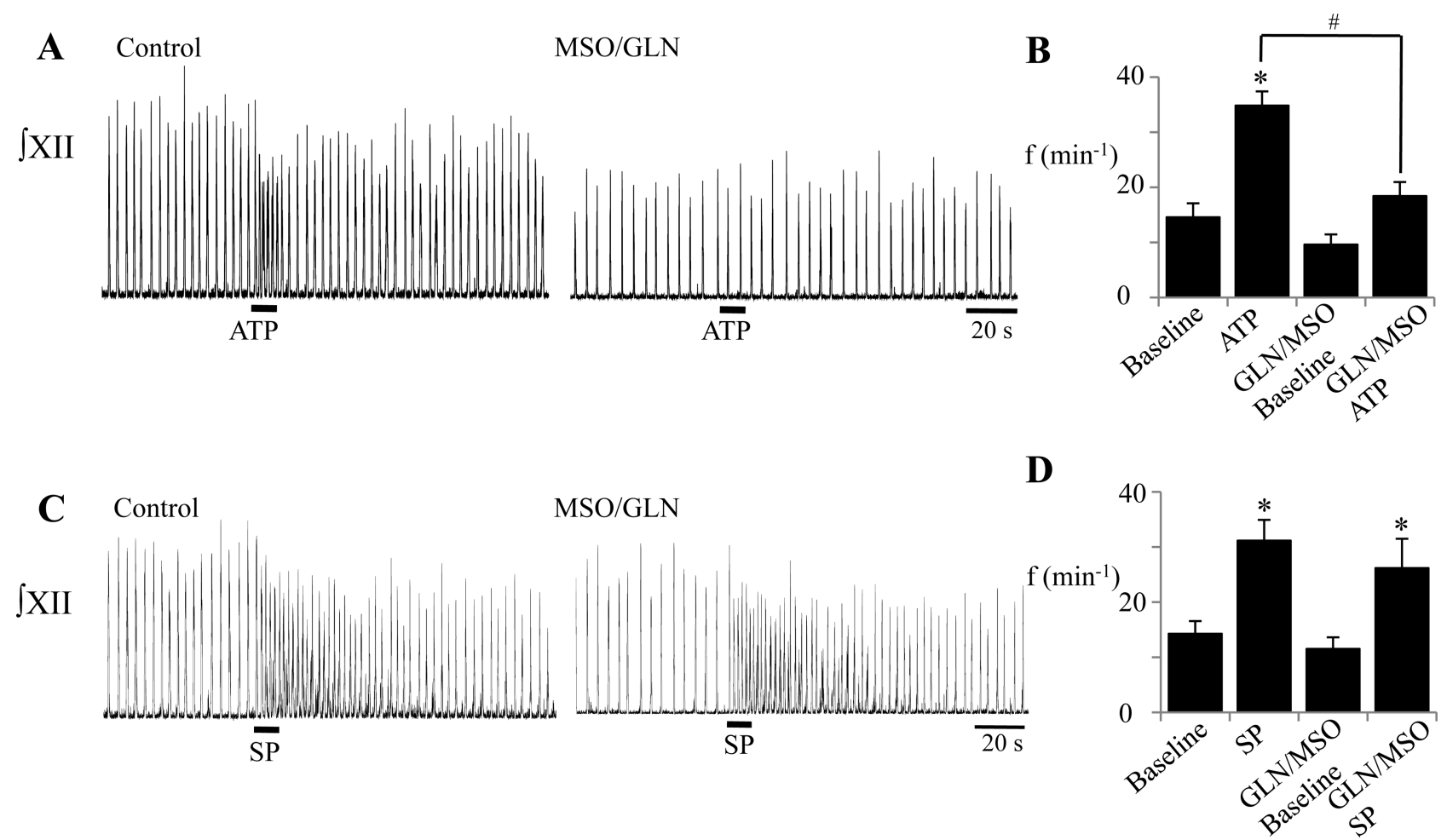

Figure 1. The influence of the glial toxin MSO $(0.1 \mathrm{~mm})$ on frequency increases evoked by ATP and SP in rhythmic medullary slice preparations. Local application of ATP $(0.1 \mathrm{~mm}, 10 \mathrm{~s}, A)$ and SP $(1 \mu \mathrm{M}, 10 \mathrm{~s}, \mathrm{C})$ in the preBötC during control conditions (left panels) and in the presence of MSO and GLN (1.5 mM, middle panels). Group data $(n=7)$ for the changes in frequency associated with ATP $(\boldsymbol{B})$ and SP $(\boldsymbol{D})$ applications. ${ }^{*} p<0.001$, significant difference from baseline or GLN/MSO baseline; ${ }^{*} p<0.001$, significant difference between ATP responses.

$34.8 \pm 2.6$ bursts/min; however, in the presence of MSO/GLN ATP no longer evoked a significant increase in frequency. Frequency was $9.6 \pm 1.8$ bursts/min in control and $18.4 \pm 2.6$ bursts/ min in MSO/GLN (Fig. $1 A, B)(n=7$, one-way ANOVA, Tukey's multiple-comparison test). In contrast, the SP (1 $\mu \mathrm{M}, 10 \mathrm{~s})$ response was not affected by MSO/GLN (Fig. 1C,D). SP caused frequency to increase from $14.3 \pm 2.3$ to $31.2 \pm 3.8 \mathrm{bursts} / \mathrm{min}$ in control conditions and from $11.5 \pm 2.1$ to $26.2 \pm 5.3 \mathrm{bursts} / \mathrm{min}$ in MSO/GLN (Fig. 1D) (one-way ANOVA, Tukey's multiplecomparison test).

These experiments were repeated using the FA toxin, instead of MSO. The ATP-evoked peak frequency response in control conditions ( $14.3 \pm 1.0$ bursts $/ \mathrm{min}$ to $32.0 \pm 3.3 \mathrm{bursts} / \mathrm{min})$ was significantly reduced in FA/GLN ( $10.9 \pm 1.0$ to $22.8 \pm 2.3$ bursts/ min) (Fig. $2 A, B)$. In contrast, the SP-evoked peak frequency response in control conditions $(12.0 \pm 2.3$ to $34.2 \pm 4.4$ bursts/ min) was unaffected by FA/GLN (11.2 \pm 0.8 to $31.2 \pm 4.2$ bursts/ $\min )$ (Fig. $2 C, D)(n=10$, one-way ANOVA, Tukey's multiplecomparison test).

Involvement of VRACs in the ATP-evoked frequency increase Extracellular ATP can influence glial function by activating glial volume-regulated anion channels (VRACs), which facilitate movement of gliotransmitters (ATP and excitatory amino acids) from intracellular to extracellular compartments (Mongin and Kimelberg, 2005). To test whether VRACs contribute to the ATPevoked frequency increase, we compared ATP responses in control conditions and after bath application of the VRAC inhibitor, DCPIB $(20 \mu \mathrm{M})$.

DCPIB had no effect on baseline frequency or the ATPevoked frequency increase. Baseline frequency was $19.7 \pm 1.5$, $20.8 \pm 1.2$, and $20.1 \pm 1.8$ bursts/min in control, DCPIB, and after 15 min of washout, respectively. The ATP-evoked peak frequencies were $43.7 \pm 5.1,44.7 \pm 4.0$, and $46.9 \pm 4.8$ bursts $/ \mathrm{min}$ in control, DCPIB, and after DCPIB washout, respectively (data not shown, $n=9$, one-way ANOVA).

\section{ATP sensitivity of preBötC glia}

To further explore the involvement of glia in the ATP-evoked frequency increase, we tested whether glia in the region of the preBötC have the capacity to respond directly to ATP. This was addressed in three ways.

First, multiphoton fluo- $4 \mathrm{Ca}^{2+}$ imaging of the preBötC was used to examine the ATP sensitivity of glia. Dye injection into the preBötC labeled morphologically diverse cells over an area that was 200-300 $\mu \mathrm{m}$ in diameter and within which cells could be visualized to a depth of $80 \mu \mathrm{m}$ (Ruangkittisakul et al., 2008). Our objective was to assess whether glia in respiratory regions in the brainstem are sensitive to ATP. Thus, the first step was to establish that we were recording from cells within the preBötC. This was accomplished by identifying cells with $\mathrm{Ca}^{2+}$ oscillations in synchrony with inspiratory-related XII nerve bursts, like the three shown in Figure $3 A$. Once the inspiratory cell column was functionally identified, the plane of focus was adjusted to contain the largest number of small cells (putative glia). The rhythmically active, inspiratory-related neurons identified in the first stage of this protocol were typically among the largest cells (146 \pm 28 $\mu \mathrm{m}^{2}$ ). However, they were not tested for their ATP-sensitivity because none were present in the focal plane containing the highest number of our target cells. In addition, we have previously established using whole-cell recording that most preBötC inspiratory neurons are sensitive to ATP (Lorier et al., 2008). While ATP is typically applied locally to the preBötC, it was bathapplied in these experiments to activate the largest number of 


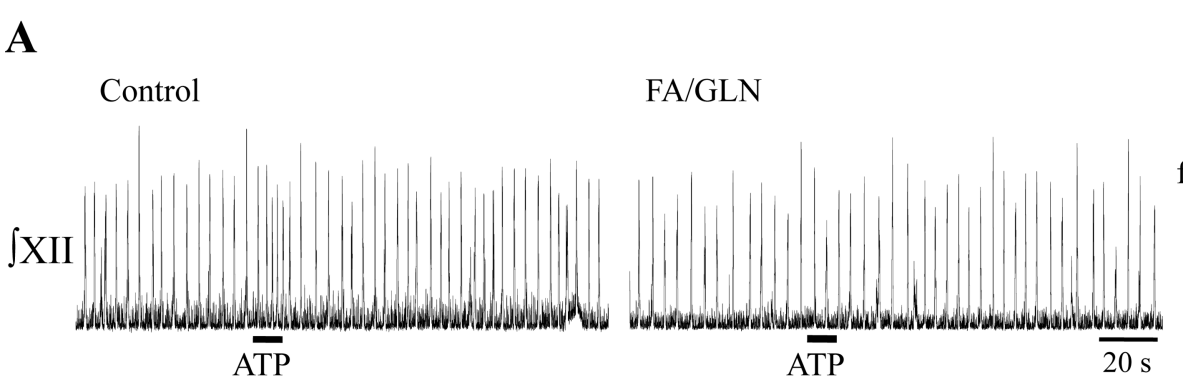

$\mathbf{C}$

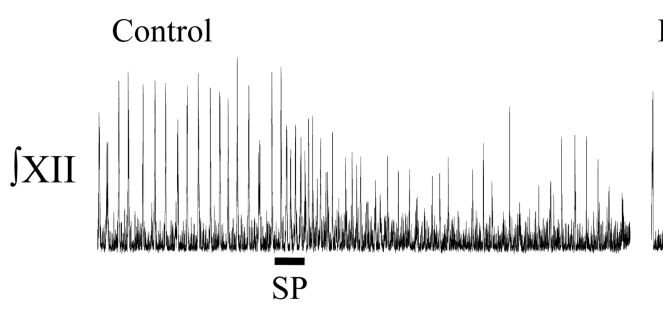

FA/GLN

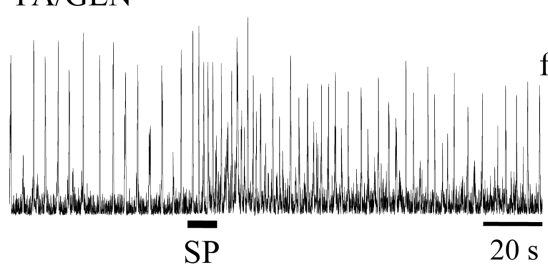

B

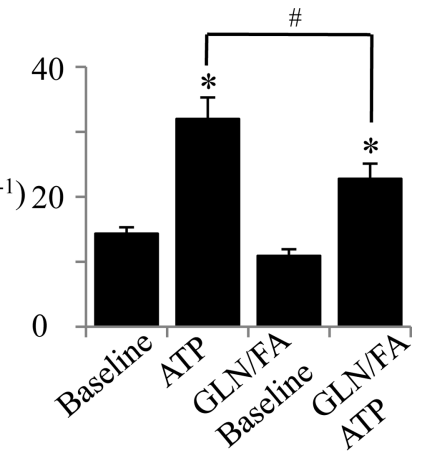

D

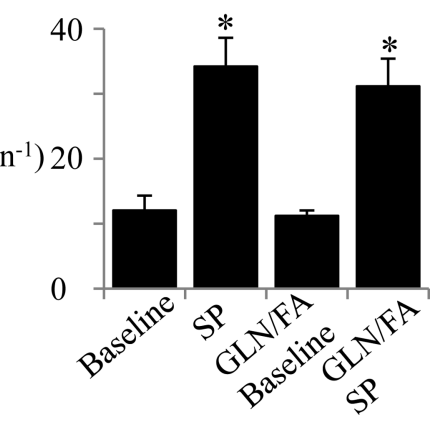

Figure 2. The influence of the glial toxin, $\mathrm{FA}(5 \mathrm{~mm})$, on the ATP- and SP-evoked frequency increases in rhythmic medullary slice preparations. Integrated XII nerve recordings after local application of ATP $(0.1 \mathrm{~mm}, 10 \mathrm{~s}, \boldsymbol{A})$ and SP $(1 \mu \mathrm{m}, 10 \mathrm{~s}, \mathrm{C})$ into the preBötC during control (left panels) and FA and GLN (1.5 mm, middle panels). Group data $(n=10)$ showing changes in the maximum frequency evoked in response to ATP $(\boldsymbol{B})$ and SP $(\boldsymbol{D})$ in control and FA/GLN. ${ }^{*} p<0.001$, significant difference from baseline or FA/GLN baseline; ${ }^{*} p<0.01$, significant difference between ATP responses.

cells possible and because minor movements of the tissue during local application changed the focal plan and confounded quantification of changes in fluorescence. Twenty-six to thirty-four cells per slice (Fig. $3 B$ ) responded to bath-applied ATP with an increase in fluorescence intensity. Since neurons and glia in this region cannot be unequivocally distinguished based on visual inspection, cells showing any detectable change in fluorescence in response to ATP application were outlined as ROIs and divided into three groups based on cross-sectional area (group 1, $\leq 50$ $\mu \mathrm{m}^{2}$; group 2, 50-100 $\mu \mathrm{m}^{2}$; group 3, $\geq 100 \mu \mathrm{m}^{2}$ ). Based on published whole-cell recording data (Grass et al., 2004) and our own whole-cell recordings from nonrhythmic, 300- $\mu$ m-thick slices (see Fig. 5), nonexcitable glia are $\leq 10 \mu \mathrm{m}$ in diameter $(\sim 80$ $\mu \mathrm{m}^{2}$ ); therefore, groups 1 and 2 were considered most likely to comprise glia.

Cells in the three groups had similar baseline fluorescence intensity but responded differently to bath-applied ATP $(0.1 \mathrm{mM})$ (Fig. 3B-D). Fluorescence in group $1(n=77$, from 5 slices) and group 2 ( $n=49$, from 5 slices) cells increased significantly from $800 \pm 41$ to $1634 \pm 79$ (an increase of $857 \pm 65$ ) and $802 \pm 41$ to $1216 \pm 72$ (an increase of $418 \pm 63$ ) fluorescence units, respectively (Fig. $3 B-D$ ). Fluorescence did not change significantly in group 3 ( $730 \pm 41$ to $922 \pm 67 ; n=20$, from 5 slices) (Fig. $3 B-D)$.

To address the possibility that these ATP responses were indirect, perhaps mediated through neuronal excitation and neurotransmitter release, ATP was applied again to the same cells but this time in the presence of a bath-applied antagonist cocktail of TTX $(0.5 \mu \mathrm{M})$ to block action potentials, and CNQX $(10 \mu \mathrm{M})$ and APV $(50 \mu \mathrm{M})$ to block AMPA and NMDA receptors, respectively. The antagonist cocktail abolished inspiratory rhythm within 3 min. The fluorescence increase (peak response-baseline) evoked by ATP after $5 \mathrm{~min}$, while significantly lower than the original response, was still significant and averaged $393 \pm 45$ and $238 \pm$
41 fluorescence units for group 1 and group 2 cells, respectively (Fig. 3D) (two-way ANOVA, Bonferroni correction). ATP responses evoked at $15 \mathrm{~min}$ intervals during antagonist washout remained constant and were similar to those seen in the antagonists (Fig. 3D).

The only unexpected result from these imaging experiments was that the largest cells (presumptive neurons) did not respond to ATP with a significant increase in $\mathrm{Ca}^{2+}$ fluorescence. Neurons, including inspiratory neurons, in the preBötC express $\mathrm{P}_{2} \mathrm{X}_{2}$ and $\mathrm{P}_{2} \mathrm{Y}_{1}$ receptors (Lorier et al., 2004, 2007). The vast majority of inspiratory neurons also respond to ATP with inward currents under whole-cell recording conditions (Lorier et al., 2008). Neurons in this region would therefore be expected to respond to ATP; however, there is greater potential for ATP hydrolysis by ectonucleotidases with bath application (Funk et al., 2008; Huxtable et al., 2009) (i.e., ATP has to diffuse through tissue, whereas with local application, it is injected into the site of interest) and for receptor desensitization/internalization (as the ATP concentration gradually increases). In addition to enzymatic breakdown and receptor desensitization, the lack of a neuronal calcium increase to bath-applied ATP can also be attributed to the fact that we are only measuring changes in intracellular calcium. ATP might be affecting the membrane potential without causing a noticeable calcium change. As such, we measured the fluo-4 fluorescence evoked by locally applied ATP to test the possibility that the nonresponsiveness of large cells was associated with bath application of ATP $(1 \mathrm{~mm})$. Given the smaller number of cells activated, they were grouped simply as large (139 $\pm 23 \mu \mathrm{m}^{2}$, range 95-201 $\mu \mathrm{m}^{2}, n=5$ ) or small $\left(61.0 \pm 3.2 \mu \mathrm{m}^{2}\right.$, range $\left.50-75 \mu \mathrm{m}^{2}, n=9\right)$. In this protocol, large and small cells responded to ATP with a significant increase in fluorescence, as shown for individual cells in Figure 4. This increase was from $1140 \pm 207$ to $1838 \pm 403$ fluores- 
cence units $(162 \pm 13 \%)$ and $1300 \pm$ 142 to $2374 \pm 203$ fluorescence units $(201 \pm 14 \%)$ in large and small cells, respectively (Fig. $4 A-C$ ).

To further establish that neuron sensitivity is not dependent on glia, we measured ATP currents of inspiratory and noninspiratory neurons in rhythmic slices under two conditions. The first, after 90 min incubation in $\mathrm{MSO}(0.1 \mathrm{~mm})$ and restoration of rhythm with GLN (1.5 mM) and the second, after adding TTX $(0.5 \mu \mathrm{M})$, CNQX $(10 \mu \mathrm{M})$, and APV $(100 \mu \mathrm{M})$ to the bath to block synaptic transmission and glutamatergic receptors. We demonstrated, as expected based on data from Lorier et al. (2008), that the neurons responded to ATP under both conditions, i.e., that neuronal ATP currents are not dependent on glutamate release from glia. As shown for a single inspiratory neuron (defined by the presence of synaptic currents in phase with rhythmic $\int$ XII activity) in Figure 4, $D$ and $E$, ATP (1 mM, $10 \mathrm{~s}$ ) evoked a current in MSO/GLN that was similar following bath application of TTX, CNQX, and APV. Group data were similar. Currents evoked by $10 \mathrm{~mm}$ ATP averaged $30 \pm 4.7 \mathrm{pA}$ in MSO/GLN and $26 \pm 7.2 \mathrm{pA}$ after TTX, CNQX, and APV. These currents were associated with $14.3 \pm 6.2 \%$ and $13.8 \pm 6.1 \%$ decreases in $R_{\mathrm{N}}$ before and after TTX, CNQX, and APV respectively. Four noninspiratory neurons tested only after addition of TTX, CNQX, and APV responded to ATP (10 $\mathrm{mm}$ ) with currents of $30 \pm 10 \mathrm{pA}$.

While ATP-evoked $\mathrm{Ca}^{2+}$ increases in group 1 and 2 cells suggest direct activation of glia by ATP, size criteria alone do not unequivocally identify glia. Thus, to further test whether glia can respond directly to ATP, we used whole-cell recording to target nonexcitable cells (that could not fire action potentials) with morphology similar to that described previously (Grass et al., 2004). ATP (0.1 mM, $30 \mathrm{~s})$ or the $\mathrm{P}_{2} \mathrm{Y}_{1} \mathrm{R}$ agonist $(0.1 \mathrm{mM}$ MRS 2365, $30 \mathrm{~s})$ was applied to 8 cells $(<10 \mu \mathrm{m}$ diameter) in total (ATP to 7 cells and MRS 2365 to 5 cells). ATP and MRS 2365 responses were pooled as P2R agonist-evoked currents because the ATP- and MRS 2365evoked currents were similar and if a cell responded to ATP, it also responded to MRS 2365. Cells fell into two categories based on their ATP sensitivity, input resistance $\left(R_{\mathrm{N}}\right)$, and resting potential. The first group responded to $\mathrm{P} 2 \mathrm{R}$ agonists with average currents of $36 \pm 6 \mathrm{pA}(n=4)$, as shown for a single cell in Figure $5 A$. This group had low $R_{\mathrm{N}}$ values $(23 \pm 2 \mathrm{M} \Omega)$ and resting membrane potentials of $-68 \pm 0.8 \mathrm{mV}$, depolarized compared to other work (Grass et al., 2004) due to elevated extracellular $\mathrm{K}^{+}$ used here. The second group of cells $(n=4)$ did not respond to $\mathrm{P} 2 \mathrm{R}$ agonists. These cells had higher $R_{\mathrm{N}}(289 \pm 37 \mathrm{M} \Omega)$ and significantly more depolarized resting membrane potentials $(-59 \pm 2 \mathrm{mV})$. The relationship between $\mathrm{P} 2 \mathrm{R}$ agonist-evoked current amplitude and

B
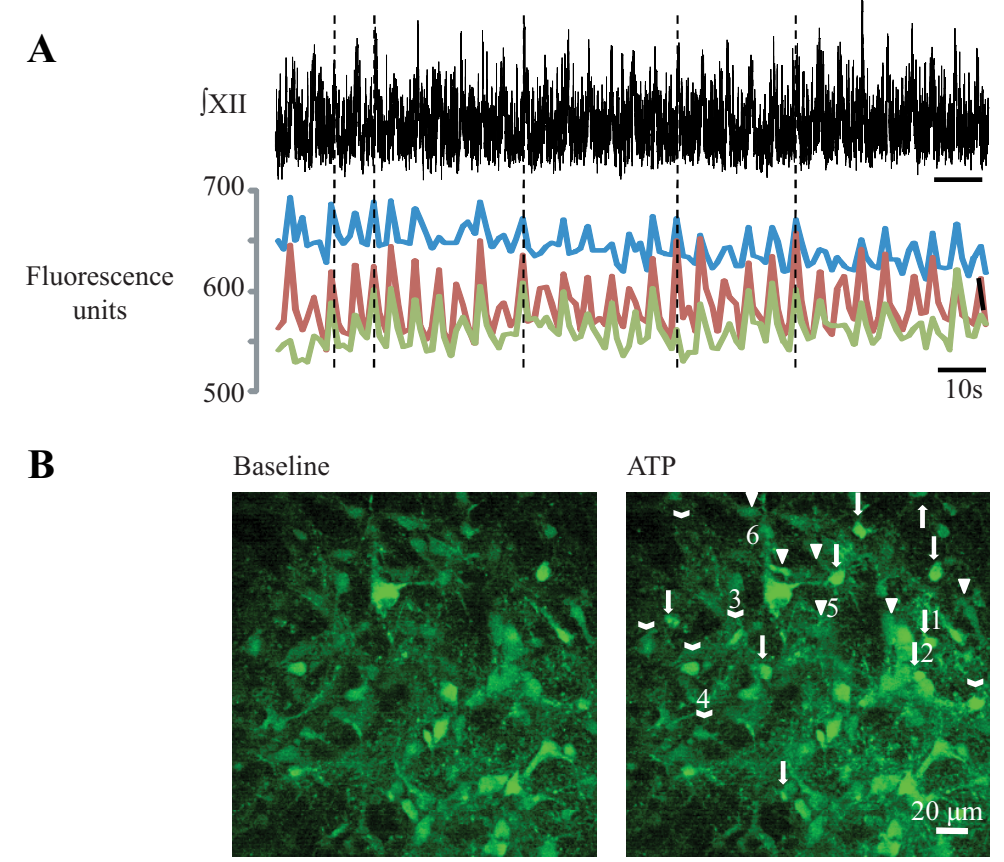

C

Figure 3. Multiphoton imaging of fluo-4 $\mathrm{Ca}^{2+}$ fluorescence showing sensitivity of preBötC cells at a single optical plain to bath-applied ATP. A, Small fluorescence oscillations recorded from 3 cells in-phase with rhythmic bursts of activity recorded from the XII nerve in the same $x-y$ plane as cells shown in $\boldsymbol{B}$ but slightly more superficial. $\boldsymbol{B}$, Multiphoton images of the preBötC showing different cross-sectional areas are indicated with the following symbols: $\downarrow$, cells $\leq 50 \mu \mathrm{m}^{2} ; \vee, 50-100 \mu \mathrm{m}^{2} ; \boldsymbol{\nabla}, \geq 100 \mu \mathrm{m}^{2}$. (lite bascence (white bars), peak fluorescence values evoked by ATP (black bars, $0.1 \mathrm{~mm}, 30 \mathrm{~s}$ ), peak fluorescence values evoked by ATP in the presence of TTX, CNQX, and APV (dark gray bars, $0.5 \mu \mathrm{m}, 0.1 \mathrm{~mm}$, and $0.05 \mathrm{~mm}$ respectively), and the ATP response after antagonist washout (light gray bars). ${ }^{*} p<0.001$, significant difference from baseline; ${ }^{\#} p<0.05$, ${ }^{\# \#} p<0.001$, significant difference from ATP response; ${ }^{@} p<0.001$, significant difference from $\leq 50 \mu \mathrm{m}^{2}$ cell ATP response. cell $R_{\mathrm{N}}$ is plotted for each cell in Figure $5 B(n=8)$ and reveals distinct groups. Glutamate ( $1 \mathrm{~mm}, 200-500 \mathrm{~ms})$ was applied as a control to assess cell viability. Low $(-98 \pm 13 \mathrm{pA}, n=2)$ and high $(-91 \pm 48$ $\mathrm{pA}, n=2) R_{\mathrm{N}}$ cells responded similarly to glutamate.

Even with whole-cell recording, the possibility remains that glial responses in tissue slices are mediated indirectly through neuronal activation and neurotransmitter release. To eliminate the possibility of secondary activation, primary cultures of glia from the ventral medulla at the rostrocaudal level of the preBötC were produced to test the ATP sensitivity of these cells in isolation. We confirmed the glial composition of cultures using immunocytochemistry with antibodies against two common glial markers (S100 $\beta$ and GFAP), a neuronal marker (NF-160), and Hoechst staining to label cell nuclei (data not shown). The ma- 
A
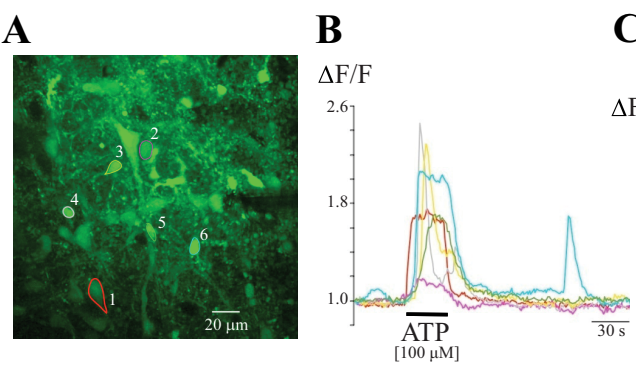

C

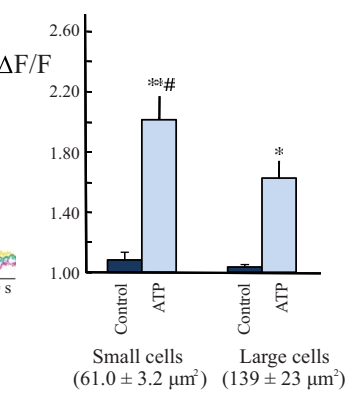

D

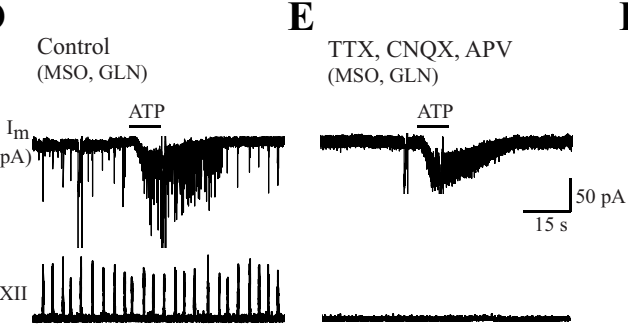

$\mathbf{F}$

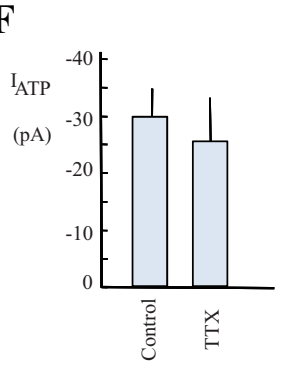

Figure 4. Multiphoton imaging of fluo-4 $\mathrm{Ca}^{2+}$ fluorescence showing sensitivity of preBötC cells at a single optical plain to locally applied ATP. A, Multiphoton image of the preBötC showing baseline fluo-4 fluorescence of multiple cells. Six cells are color coded, and the time courses of their fluorescence responses to locally applied ATP (100 $\mu \mathrm{M}, 30 \mathrm{~s})$ are shown in $\boldsymbol{B}$. Red and pink cells have areas $>100 \mu \mathrm{m}^{2}$. C, Group data showing peak fluorescence responses to locally applied aCSF (control) and ATP of small ( $n=$ 9) and large $(n=5)$ cells. $D$, Response of an inspiratory neuron to locally applied ATP $(1.0 \mathrm{~mm}, 10 \mathrm{~s})$ after incubating the slice in MSO $(0.1 \mathrm{~mm})$ for $90 \mathrm{~min}$ and recovering rhythm with GLN $(1.5 \mathrm{~mm}) . \boldsymbol{E}$, Response of the same neuron $15 \mathrm{~min}$ later after bath application of TTX $(0.5 \mu \mathrm{M})$, CNQX (10 $\mu \mathrm{M})$, APV $(100 \mu \mathrm{M}) .{ }^{* *} p<0.001,{ }^{*} p<0.01$, significant difference between control (aCSF) and ATP; ${ }^{\#} p<0.05$, significant difference between small and large cells.

jority $(>90 \%)$ of cells cultured from the ventral medulla on 5 occasions were positive for both glial markers. These cultures were devoid of NF-160 staining, but $5-10 \%$ of cells identified by Hoechst staining did not stain for glial markers.

To determine the P2R sensitivity of ventral medullary glia, cells were loaded with fluo-4 AM and visualized under DIC optics (Fig. 6A). The triple-barreled pipette was positioned $10-20 \mu \mathrm{m}$ above the coverslip, upstream of a cluster of cells (orientation shown in Fig. 6A), and changes in fluorescence monitored following local drug application. Local application of ATP (0.01 $\mathrm{mM}, 10 \mathrm{~s}$ ) caused a significant increase in fluorescence from a baseline of $91 \pm 5$ to an average peak of $196 \pm 11$ fluorescence units (Fig. $6 C)(n=98$, from 3 coverslips, two-way ANOVA, Bonferroni correction). SP (1 $\mu \mathrm{M}, 10 \mathrm{~s})$, on the other hand, evoked small fluorescent increases in some cells, but when averaged over the population these changes in fluorescence $(90 \pm 5$ to $111 \pm 7$ fluorescence units) were not significant (Fig. 6C) $(n=$ 98, from 3 coverslips, two-way ANOVA, Bonferroni correction).

Given the potential for heterogeneity in glial properties between regions, we examined glia cultured specifically from preBötC punches. The occasional NF-150 immunolabeled, neuronlike cell could survive in these cultures, but had morphology (cell bodies of $20-25 \mu \mathrm{m}$ with multiple processes) distinct from any cells used in these $\mathrm{Ca}^{2+}$ imaging experiments. Imaged areas were devoid of this neuron-like cell type.

Since $\mathrm{P}_{2} \mathrm{Y}_{1}$ Rs are the main subtype underlying the frequency increase evoked by ATP in the preBötC (Lorier et al., 2007), we tested in both culture types the hypothesis that $\mathrm{P}_{2} \mathrm{Y}_{1}$ Rs contribute to the ATP-evoked increase in intracellular $\mathrm{Ca}^{2+}$. In ventral medullary cultures, local application of ATP $(0.01 \mathrm{~mm}, 10 \mathrm{~s})$ evoked a $3.53 \pm 0.29$-fold increase in fluorescence (data not shown). When preceded by a $90 \mathrm{~s}$ application of the $\mathrm{P} 2 \mathrm{Y}_{1} \mathrm{R}$ antagonist $(0.5$

mM MRS 2279) the ATP-evoked change in $\mathrm{Ca}^{2+}$ was significantly reduced to a $2.79 \pm 0.29$-fold increase that recovered toward control levels $(3.53 \pm 0.031$-fold increase) after $10 \mathrm{~min}$ of antagonist washout (data not shown, $n=20$, from 3 coverslips, one-way ANOVA, Bonferroni correction). The $\mathrm{P} 2 \mathrm{Y}_{1} \mathrm{R}$ agonist, MRS $2365(1 \mu \mathrm{M}, 10 \mathrm{~s})$ caused a significant $5.0 \pm 0.5$-fold fluorescence increase in glia ( $n=28,5$ coverslips, paired $t$ test) to a maximum of $177 \pm 45$ fluorescence units from a baseline level of $37 \pm 9$ fluorescence units (data not shown). This increase was significantly reduced to a $3.1 \pm$ 0.4 -fold increase by $90 \mathrm{~s}$ preapplication of MRS 2279 (0.5 mM, a P2 $\mathrm{Y}_{1} \mathrm{R}$ antagonist, $n=28$, from 5 coverslips). After $10 \mathrm{~min}$ of washout, the MRS 2365 response partially recovered to a $4.0 \pm 0.4$-fold increase (data not shown). P2 $\mathrm{Y}_{1} \mathrm{R}$ sensitivity was further supported with immunocytochemical analysis of fixed cultures, which demonstrated that cultured cells labeled for both $\mathrm{S} 100 \beta$ and the $\mathrm{P}_{2} \mathrm{Y}_{1} \mathrm{R}$ (Fig. 7) ( $n=4$ coverslips). Local application of ATP $(0.01 \mathrm{~mm}, 10 \mathrm{~s})$ to the preBötC punches caused a significant, $2.4 \pm 0.1$ fold increase, in cell fluorescence from $66 \pm 3$ to $154 \pm 9$ fluorescence units (Fig. 6).

In preBötC cultures, local application of ATP $(0.01 \mathrm{~mm}$, $10 \mathrm{~s}$ ) caused a significant, $2.4 \pm 0.1$-fold, increase in cell fluorescence from $66 \pm 3$ to $154 \pm 9$ fluorescence units (Fig. 8). However, this increase was significantly reduced by a $90 \mathrm{~s}$ preapplication of MRS $2279(0.5 \mathrm{~mm})$ to a $1.4 \pm 0.1$-fold increase (Fig. 8). The antagonism was reversible, recovering to a $2.3 \pm 0.1$-fold increase $15 \mathrm{~min}$ after antagonist washout (Fig. $8 A-C$ ) (one-way ANOVA, Bonferroni correction). Similarly, MRS $2365(0.001 \mathrm{~mm}, 10 \mathrm{~s})$ caused a $2.8 \pm 0.1$-fold fluorescence increase that was reduced to a $1.3 \pm 0.03$-fold increase by MRS 2279 and recovered to a $2.5 \pm 0.1$-fold increase after $15 \mathrm{~min}$ of antagonist washout (Fig. 8D) (one-way ANOVA, Bonferroni correction).

The increase in fluorescence after MRS 2279 and either ATP or MRS 2365 in the preBötC cultures was not significantly different from baseline fluorescence (Fig. 8C,D). This was not the case, however, with the ventral medullary cultures (described above) in which a significant fluorescence response persisted in the presence of MRS 2279. To assess whether this might reflect contribution of non- $\mathrm{P} 2 \mathrm{Y}_{1}$ Rs to the ATP response in ventral medullary cultures, we compared the block produced by MRS 2279 alone and then in combination with PPADS $(100 \mu \mathrm{M})$ and suramin $(500 \mu \mathrm{M})$. ATP evoked a $2.45 \pm$ 0.12 -fold increase in fluorescence (Fig. $8 \mathrm{E}$ ). This was reduced to a $1.97 \pm 0.08$-fold increase by MRS 2279 in combination with PPADS and suramin, which was a bigger reduction than that produced by MRS 2279 alone ( $1.84 \pm 0.07, n=52$ cells from 4 cultures).

\section{Release of glutamate from primary glial cultures}

While the preceding data demonstrate that glia in, or cultured from, the preBötC respond to ATP with an outward current or an 
increase in intracellular $\mathrm{Ca}^{2+}$, the glia need to release excitatory agents to influence inspiratory neurons, and in turn network activity. Given that ATP evokes glutamate release from glia (Parpura et al., 1994; Araque et al., 2000; Jeremic et al., 2001; Domercq et al., 2006) and that glutamate in the preBötC potently increases inspiratory frequency (Greer et al., 1991; Smith et al., 1991; Funk et al., 1993), we hypothesized that glia from the ventral medulla at the level of the preBötC release glutamate in response to ATP. To test this, we used HPLC to measure glutamate concentration in culture media at time 0 and after $5 \mathrm{~min}$ incubation in either aCSF, ATP, or ATP and a P2R antagonist cocktail $(0.5 \mathrm{~mm}$ suramin, $0.1 \mathrm{~mm}$ PPADS, $0.5 \mathrm{~mm}$ MRS 2279). At $5 \mathrm{~min}$, glutamate levels in aCSF were at $0.92 \pm$ $0.05(n=12)$ of levels at time 0 . In contrast, ATP evoked a $1.90 \pm 0.26$-fold increase (Fig. 9) $(n=12$, one-way ANOVA, Tukey's multiple comparison) in glutamate concentration. Importantly, this ATP-evoked increase in glutamate was abolished $(0.94 \pm 0.16$ of time 0 levels) when ATP was coapplied with the P2R antagonist cocktail (Fig. 9) ( $n=10$, one-way ANOVA, Tukey's multiple comparison), indicating that the glutamate release was dependent on $\mathrm{P} 2 \mathrm{R}$ activation.

\section{Discussion}

Glia are necessary for maintaining inspiratory network activity (Hülsmann et al., 2000), but until now the role of gliotransmission in modulating inspiratory network activity has not been examined. Abundant evidence indicate that glia influence neuronal excitability, but understanding how glia influence neuronal networks is limited and includes their involvement in synapse formation and elimination (Haydon and Carmignoto, 2006; He and Sun, 2007), changes in synaptic efficacy (Zhang et al., 2003; Gordon et al., 2005), and sleep regulation (Halassa et al., 2009). We present evidence that modulation of inspiratory network activity by ATP does not just occur through neurons (Lorier et al., 2008), but also through glia.

The block of the ATP-evoked frequency increase by the glial toxin MSO, and its significant attenuation by FA, strongly implicate glia in this response. Whether the actions of these toxins result exclusively from their actions on glia or through secondary mechanisms is controversial. The fact that MSO more effectively inhibits the ATP-evoked frequency response suggests that either MSO is more effective in
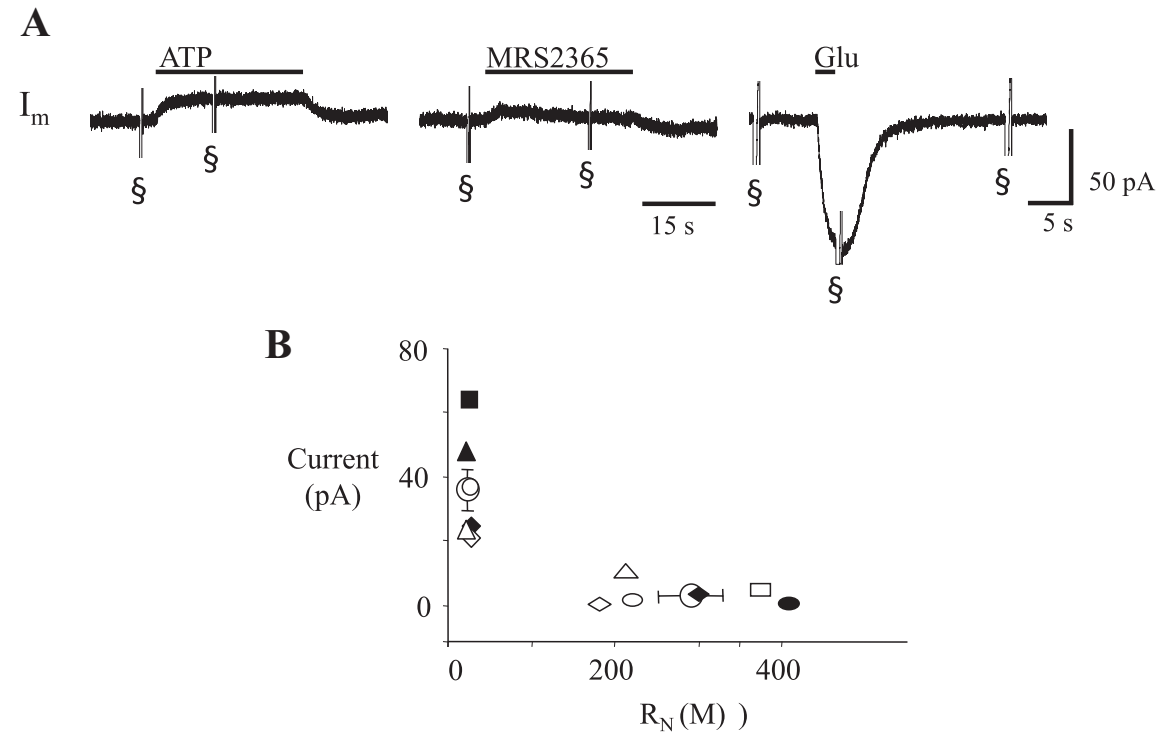

Figure 5. Whole-cell voltage-clamp recordings from glia in the preBötC. $A$, Membrane current responses of a single glial cell to local application of ATP ( $0.1 \mathrm{~mm}, 30 \mathrm{~s}$, left), a P2Y ${ }_{1}$ R agonist ( $0.1 \mathrm{~mm}$ MRS $2365,30 \mathrm{~s}$, middle), and glutamate ( $1 \mathrm{~mm}, 2 \mathrm{~s}$, right). $\boldsymbol{B}$, Group data $(n=8)$ showing the relationship between maximum agonist-evoked current and input resistance $\left(R_{N}\right)$; each symbol type represents a different cell; open symbols represent ATP responses; closed symbols represent responses to MRS 2365 in the same cell; circles represent averaged data. § indicates current response to a voltage ramp.
A DIC

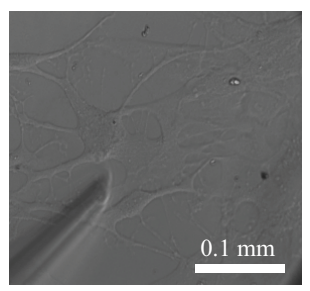

B

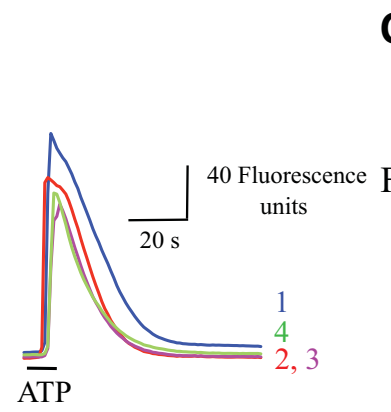

Baseline

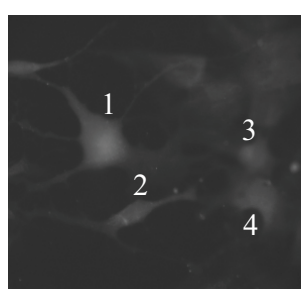

C
Figure 6. Glia cultured from the ventrolateral medulla respond to locally applied ATP $(0.01 \mathrm{~mm}, 10 \mathrm{~s})$ with an increase in fluo-4 $\mathrm{Ca}^{2+}$ fluorescence. $A, \mathrm{DIC}$ image of cultured glia and the position of the drug pipette (left panel). Epifluorescence image of cells in left panel showing baseline fluorescence (middle panel) after incubation with fluo-4 AM (10 $\mu \mathrm{M}$ ) and during local application of ATP (right panel). B, Traces showing the time course of changes in intracellular $\mathrm{Ca}^{2+}$ measured in 4 ROls (numbered 1-4) in $\boldsymbol{A}$. C, Group data $(n=98)$ showing a significant increase in fluorescence in response to ATP, but not SP. ${ }^{*} p<0.001$, significant difference from baseline; ${ }^{\#} p<0.001$, significant difference from ATP response.
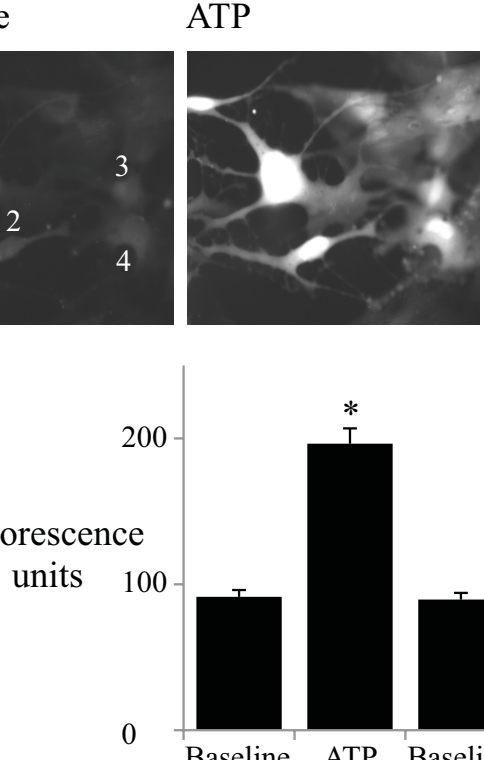

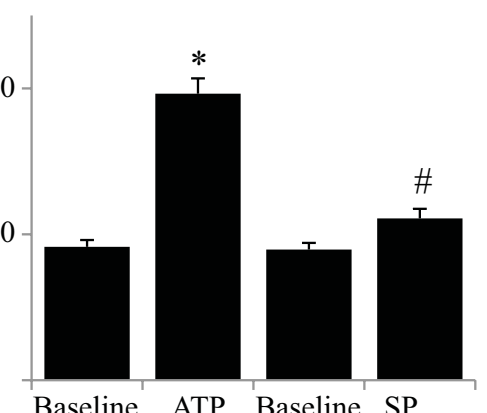

Baseline ATP Baseline SP

blocking glia or that nonglial actions of MSO account for its greater efficacy. The toxins had similar effects on baseline rhythm in our experiments, but previous data in rhythmic slices showed that after $60 \mathrm{~min}$ FA reduced frequency to $47.4 \pm 7.1 \%$ of control, while MSO reduced frequency to $5.3 \pm 5.3 \%$ (Hülsmann et al., 

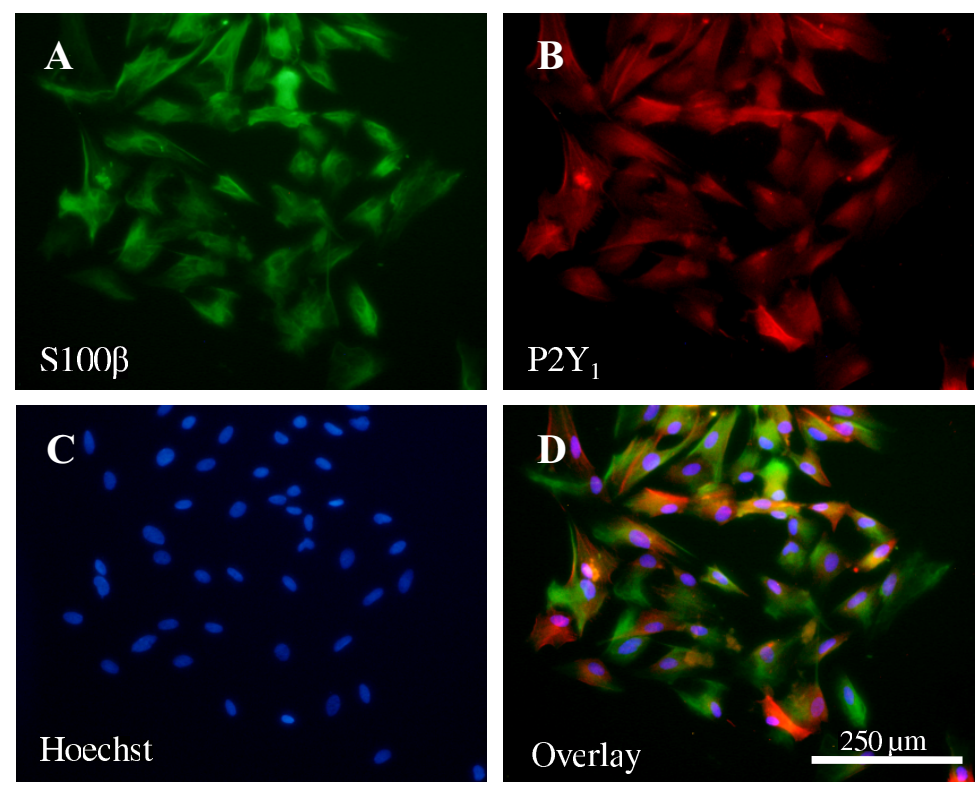

Figure 7. Glia cultured from the ventrolateral medulla express immunolabeling for the $P 2 Y_{1} R$. Epifluorescence images of a glial culture showing immunolabeling for the glial marker $\mathrm{S} 100 \beta$ (monoclonal anti-S-100 $\beta$-subunit antibody with Alexa Fluor 488 donkey anti-mouse $\operatorname{lgG}, A$ ) and the $P 2 Y_{1} R$ (rabbit anti-P2Y, with Alexa Fluor 594 donkey anti-rabbit lgG, B). C, Hoechst staining of cell nuclei. $\boldsymbol{D}$, The overlay of $\boldsymbol{A}-\boldsymbol{C}$

2000). While these data suggest that MSO is more effective at blocking rhythm, and our data indicate that MSO is more effective at blocking the ATP response, they do not establish that MSO has a greater ability to disrupt glial function. The important point is that two glial toxins, operating through different mechanisms, both inhibit the ability of ATP to excite preBötC inspiratory networks, supporting a glial contribution to the network response.

Recent work suggests that the acute actions of MSO and FA are in fact mediated primarily though glia. First, FA induced inward currents or depolarizations in glia but had no effect on XII MNs (Hülsmann et al., 2000). Second, a side-effect of systemically applied MSO is glycogen deposition in cranial motoneurons of neonatal rat (Young et al., 2005). While the impact of glycogen on neuron and network function is unclear, it is unlikely of significance as the deposition occurs on a time scale (days) much slower than relevant to our manipulations. Third, FA and MSO increase extracellular $\mathrm{K}^{+}$(Largo et al., 1997). Again, however, this is unlikely a factor in our experiments as it would enhance inspiratory rhythm and motor output of rhythmic slices rather than impair it.

The most compelling evidence supporting involvement of glia in the ATP-evoked increase in inspiratory frequency is that while glial toxins altered the effects of ATP on frequency, the sensitivity of preBötC networks to SP persisted; i.e., the toxins did not affect what is most likely a neuronally mediated response. Supporting the neuronal nature of the SP response is that preBötC neurons critical for rhythm generation are excited by SP and express NK1Rs (Gray et al., 1999, 2001). In addition, glia cultured from the preBötC have minimal SP sensitivity (Fig. 6), which is consistent with recent observations in slices that only a portion of glia in the preBötC region respond to SP with small increases in intracellular $\mathrm{Ca}^{2+}$ (Härtel et al., 2009). Furthermore, while cultured glia express NK1R mRNA (Too et al., 1994), glia in guinea pig (Yip and Chahl, 2001) and human brain (Tooney et al., 2000) do not express NK1R protein.
While it remains possible that SP alters glial activity without changing intracellular $\mathrm{Ca}^{2+}$, the persistence of the neuronally mediated SP response strongly supports the glial specificity of the toxins.

At the same time, however, the fact that one of the toxins (FA) only reduced the ATP response raises the possibility that neurons contribute. In fact, the moderate and almost ubiquitous sensitivity of preBötC inspiratory neurons to ATP (Lorier et al., 2008) combined with the sensitivity of preBötC neurons to ATP in the presence of MSO, TTX, and glutamate receptor antagonists suggests that the ATP response is most likely mediated through activation of both neurons and glia. Data also suggest that while glia are not required for all modulators (e.g., SP) to influence inspiratory rhythm, they are important to the ATP response.

Our hypothesis that glia contribute to the ATP response is further supported by numerous lines of evidence that preBötC glia show P2R-dependent ATP sensitivity. To begin, ATP responses do not involve VRACs. From this point, delineating glial from neuronal drug actions in an intact network is difficult since glia and neurons release many of the same transmitters (e.g., glutamate and ATP) and express the same receptors (Porter and McCarthy, 1997; Deitmer et al., 1998). We used multiple techniques to confirm ATP sensitivity of preBötC glia. Multiphoton $\mathrm{Ca}^{2+}$ imaging in rhythmic slices established that small preBötC cells respond to ATP with increased intracellular $\mathrm{Ca}^{2+}$. As size criteria alone do not positively identify glia, whole-cell recording data were important to demonstrate that small, nonexcitable preBötC cells with electrical properties similar to previously identified astrocytes (Grass et al., 2004) are sensitive to P2R modulation. Lack of a detectable ATP response in half of the nonexcitable cells supports heterogeneity of glia (Grass et al., 2004), but does not necessarily indicate that cells are insensitive to ATP, only that P2R stimulation did not evoke a change in membrane current. It is also possible that the ATP-insensitive cells are oligodendrocytes, as these also have high input resistance values (Chvátal et al., 2004; Káradóttir et al., 2008). However, our data do not allow unequivocal discrimination because at the ages studied here (P0-P4) astrocyte precursor cells, astrocytes, oligodendrocyte precursor cells, and oligodendrocytes all fit within the size range of recorded cells.

Since the multiphoton and whole-cell experiments were performed in brain slices, the possibility remains that responses reflect indirect activation of glia by ATP-evoked neurotransmitter release. The P2R sensitivity of glia cultures derived from the VLM and preBötC was therefore instrumental in establishing direct ATP sensitivity of glia. Culturing of cells can induce changes in gene transcription and receptor expression (Kimelberg et al., 1997). However, the properties of glial receptors (including P2Rs) measured in vitro are often unchanged in culture (Neary et al., 1988). Thus, while we cannot exclude the possibility that the responses in culture reflect altered $\mathrm{P} 2 \mathrm{R}$ expression, the culture data are consistent with $\mathrm{Ca}^{2+}$ imaging and whole-cell electro- 
physiology data, and strongly support a sensitivity of preBötC glia to ATP, in part through $\mathrm{P}_{2} \mathrm{Y}_{1}$ Rs.

Involvement of glia in the ATP-evoked frequency increase is further supported by our demonstration of ATP-evoked, P2Rdependent glutamate release. Since glutamate potently excites inspiratory rhythm (Greer et al., 1991; Funk et al., 1993, 1997), we propose that activation of glial P2Rs increases intracellular $\mathrm{Ca}^{2+}$ (as shown using multiphoton imaging of slices and $\mathrm{Ca}^{2+}$ imaging in culture) and evokes glutamate release, which in turn activates preBötC neurons, causing a frequency increase. Changes in intracellular $\mathrm{Ca}^{2+}$ are associated with gliotransmitter release (including glutamate and ATP) in glia cultures from multiple brain regions (Araque et al., 2000; Coco et al., 2003; Fiacco and McCarthy, 2006). In addition to local release of glutamate from individual glia, ATP could also influence preBötC activity by inducing $\mathrm{Ca}^{2+}$ oscillations in glial networks, which could produce widespread glutamate release (Deitmer et al., 1998; Fiacco and McCarthy, 2006; Haydon and Carmignoto, 2006). While we have demonstrated that glia contribute to the respiratory network ATP response, directly respond to ATP, and release glutamate in response to ATP, this does not exclude a contribution from other gliotransmitters.

At present, hypoxia is the only physiological stimulus known to cause ATP release within the ventrolateral medulla, where it offsets the hypoxic ventilatory depression (Gourine et al., 2005). Based on previous data and those presented here, we propose that the increase in frequency associated with ATP and $\mathrm{P} 2 \mathrm{Y}_{1} \mathrm{R}$ activation in the preBötC is due to combined actions on neurons and glia. Direct P2R activation of preBötC neurons will cause membrane depolarization or increased excitability and a frequency increase (Lorier et al., 2007, 2008). Direct activation of preBötC glia will evoke the release of glutamate (and perhaps other gliotransmitters), which will depolarize preBötC neurons causing frequency to increase. Both actions, neuronal and glial, may then attenuate the hypoxic ventilatory depression.

In summary, we demonstrate that glia contribute to the purinergic excitation of preBötC rhythm generating networks and propose that this contribution involves the direct activation of glial P2Rs and glutamate release. While it is widely accepted that glia play significant and diverse roles in modulating the activity of neurons, the difficulty of discretely manipulating neurotransmission versus gliotransmission means that the physiological significance of gliotransmission in modulating activity of functionally identified, behaving, mammalian neural networks is poorly understood. Our data are significant in that they demonstrate a contribution of glia to the neurochemical modulation of the
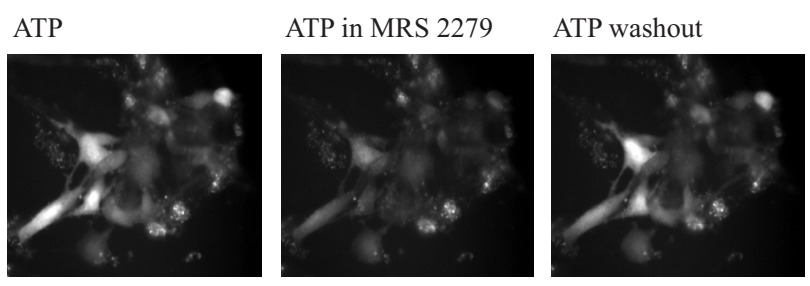

ATP in $\mathrm{TP}(0.01 \mathrm{mM})$ MRS $2279(0.5 \mathrm{mM})$

ATP Washout (15 min)

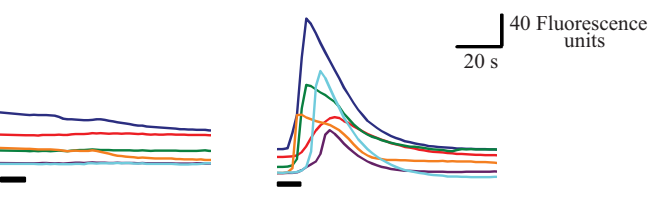

D

E
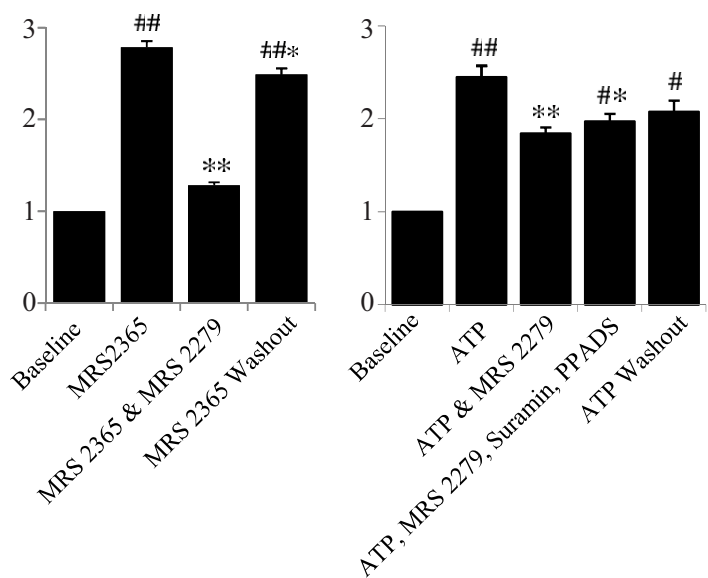

Figure 8. Glia cultured from preBötC punches respond to ATP with an increase in fluo-4 $\mathrm{Ca}^{2+}$ fluorescence. $A$, Epifluorescence images showing the fluo- 4 signal under baseline conditions (left panel), during local application of ATP (0.01 mM,

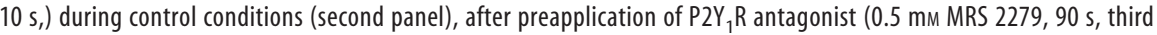
from 6 ROls (numbered in $\boldsymbol{A}$ ) in control (left), in MRS 2279 (middle), and during washout (right). $\boldsymbol{C}$, Group data $(n=63)$ showing relative changes in fluorescence in response to ATP and to ATP in the presence of MRS 2279. $D$, Group data ( $n=$ MRS 2365 in the presence of MRS $2279 .{ }_{1}$ Group change in fluorescence evoked by ATP alone, in the presence of MRS 2279, in MRS 2279 and PPADS (100 $\mu \mathrm{M})$ and suramin $(500 \mu \mathrm{M})$, and during washout. ${ }^{\# \#} p<0.001,{ }^{\#} p<0.05$, significant difference from baseline; ${ }^{*} p<0.01,{ }^{* *} p<0.001$, significant difference from peak.

Figure 9. ATP evokes glutamate release from ventrolateral medulla glia cultures. The glutamate concentration in the culture media was measured using HPLC at time 0 and after 5 min incubation periods in either aCSF (control, $n=12)$, ATP $(0.05 \mathrm{~mm}, n=12)$, or ATP with a cocktail of P2R antagonists ( $0.5 \mathrm{~mm}$ suramin, $0.1 \mathrm{~mm}$ PPADS, $0.5 \mathrm{~mm}$ MRS 2279, $n=10$ ). Levels are reported relative to values at time $0 .{ }^{\#} p<0.01$, significant difference from ATP-evoked glutamate; ${ }^{*} p<0.001$, significant difference from control. 
functioning mammalian brainstem network that generates inspiratory rhythm. This raises important questions about the potential involvement of glia in modulating activity of other motor behaviors. In addition, given the complement of receptors that glia express (Porter and McCarthy, 1997; Deitmer et al., 1998), glial modulation of network activity is likely to extend beyond purinergic signaling.

\section{References}

Abbracchio MP, Boeynaems JM, Barnard EA, Boyer JL, Kennedy C, MirasPortugal MT, King BF, Gachet C, Jacobson KA, Weisman GA, Burnstock G (2003) Characterization of the UDP-glucose receptor (renamed here the $\mathrm{P} 2 \mathrm{Y} 14$ receptor) adds diversity to the $\mathrm{P} 2 \mathrm{Y}$ receptor family. Trends Pharmacol Sci 24:52-55.

Araque A, Li N, Doyle RT, Haydon PG (2000) SNARE protein-dependent glutamate release from astrocytes. J Neurosci 20:666-673.

Burnstock G (2007) Physiology and pathophysiology of purinergic neurotransmission. Physiol Rev 87:659-797.

Chvátal A, Anderová M, Syková E (2004) Analysis of K+ accumulation reveals privileged extracellular region in the vicinity of glial cells in situ. J Neurosci Res 78:668-682.

Coco S, Calegari F, Pravettoni E, Pozzi D, Taverna E, Rosa P, Matteoli M, Verderio C (2003) Storage and release of ATP from astrocytes in culture. J Biol Chem 278:1354-1362.

Deitmer JW, Verkhratsky AJ, Lohr C (1998) Calcium signalling in glial cells Cell Calcium 24:405-416.

Domercq M, Brambilla L, Pilati E, Marchaland J, Volterra A, Bezzi P (2006) P2Y1 receptor-evoked glutamate exocytosis from astrocytes: control by tumor necrosis factor-alpha and prostaglandins. J Biol Chem 281:30684-30696.

Edwards FA, Gibb AJ, Colquhoun D (1992) ATP receptor-mediated synaptic currents in the central nervous system. Nature 359:144-147.

Espallergues J, Solovieva O, Técher V, Bauer K, Alonso G, Vincent A, Hussy N (2007) Synergistic activation of astrocytes by ATP and norepinephrine in the rat supraoptic nucleus. Neuroscience 148:712-723.

Evans RJ, Derkach V, Surprenant A (1992) ATP mediates fast synaptic transmission in mammalian neurons. Nature 357:503-505.

Feldman JL, Del Negro CA (2006) Looking for inspiration: new perspectives on respiratory rhythm. Nat Rev Neurosci 7:232-242.

Fiacco TA, McCarthy KD (2006) Astrocyte calcium elevations: properties, propagation, and effects on brain signaling. Glia 54:676-690.

Funk GD, Smith JC, Feldman JL (1993) Generation and transmission of respiratory oscillations in medullary slices: role of excitatory amino acids. J Neurophysiol 70:1497-1515.

Funk GD, Johnson SM, Smith JC, Dong XW, Lai J, Feldman JL (1997) Functional respiratory rhythm generating networks in neonatal mice lacking NMDAR1 gene. J Neurophysiol 78:1414-1420.

Funk GD, Huxtable AG, Lorier AR (2008) ATP in central respiratory control: a three-part signaling system. Respir Physiol Neurobiol 164:131-142.

Gardner-Medwin AR, Coles JA, Tsacopoulos M (1981) Clearance of extracellular potassium: evidence for spatial buffering by glial cells in the retina of the drone. Brain Res 209:452-457.

Gordon GR, Baimoukhametova DV, Hewitt SA, Rajapaksha WR, Fisher TE, Bains JS (2005) Norepinephrine triggers release of glial ATP to increase postsynaptic efficacy. Nat Neurosci 8:1078-1086.

Gourine AV (2005) On the peripheral and central chemoreception and control of breathing: an emerging role of ATP. J Physiol 568:715-724.

Gourine AV, Atkinson L, Deuchars J, Spyer KM (2003) Purinergic signalling in the medullary mechanisms of respiratory control in the rat: respiratory neurones express the P2X2 receptor subunit. J Physiol 552:197-211.

Gourine AV, Llaudet E, Dale N, Spyer KM (2005) Release of ATP in the ventral medulla during hypoxia in rats: role in hypoxic ventilatory response. J Neurosci 25:1211-1218.

Grant SL, Shulman Y, Tibbo P, Hampson DR, Baker GB (2006) Determination of d-serine and related neuroactive amino acids in human plasma by high-performance liquid chromatography with fluorimetric detection. J Chromatogr B Analyt Technol Biomed Life Sci 844:278-282.

Grass D, Pawlowski PG, Hirrlinger J, Papadopoulos N, Richter DW, Kirchhoff F, Hülsmann S (2004) Diversity of functional astroglial properties in the respiratory network. J Neurosci 24:1358-1365.
Gray PA, Rekling JC, Bocchiaro CM, Feldman JL (1999) Modulation of respiratory frequency by peptidergic input to rhythmogenic neurons in the preBotzinger complex. Science 286:1566-1568.

Gray PA, Janczewski WA, Mellen N, McCrimmon DR, Feldman JL (2001) Normal breathing requires preBotzinger complex neurokinin-1 receptorexpressing neurons. Nat Neurosci 4:927-930.

Greer JJ, Smith JC, Feldman JL (1991) Role of excitatory amino acids in the generation and transmission of respiratory drive in neonatal rat. J Physiol 437:727-749.

Halassa MM, Florian C, Fellin T, Munoz JR, Lee SY, Abel T, Haydon PG, Frank MG (2009) Astrocytic modulation of sleep homeostasis and cognitive consequences of sleep loss. Neuron 61:213-219.

Härtel K, Schnell C, Hülsmann S (2009) Astrocytic calcium signals induced by neuromodulators via functional metabotropic receptors in the ventral respiratory group of neonatal mice. Glia 57:815-827.

Haydon PG, Carmignoto G (2006) Astrocyte control of synaptic transmission and neurovascular coupling. Physiol Rev 86:1009-1031.

He F, Sun YE (2007) Glial cells more than support cells? Int J Biochem Cell Biol 39:661-665.

Hülsmann S, Oku Y, Zhang W, Richter DW (2000) Metabolic coupling between glia and neurons is necessary for maintaining respiratory activity in transverse medullary slices of neonatal mouse. Eur J Neurosci $12: 856-862$.

Huxtable AG, Zwicker JD, Poon BY, Pagliardini S, Vrouwe SQ, Greer JJ, Funk GD (2009) Tripartite purinergic modulation of central respiratory networks during perinatal development: the influence of ATP, ectonucleotidases, and ATP metabolites. J Neurosci 29:14713-14725.

Jeremic A, Jeftinija K, Stevanovic J, Glavaski A, Jeftinija S (2001) ATP stimulates calcium-dependent glutamate release from cultured astrocytes. J Neurochem 77:664-675.

Káradóttir R, Hamilton NB, Bakiri Y, Attwell D (2008) Spiking and nonspiking classes of oligodendrocyte precursor glia in CNS white matter. Nat Neurosci 11:450-456.

Kimelberg HK, Cai Z, Rastogi P, Charniga CJ, Goderie S, Dave V, Jalonen TO (1997) Transmitter-induced calcium responses differ in astrocytes acutely isolated from rat brain and in culture. J Neurochem 68:1088-1098.

Largo C, Ibarz JM, Herreras O (1997) Effects of the gliotoxin fluorocitrate on spreading depression and glial membrane potential in rat brain in situ. J Neurophysiol 78:295-307.

Lorier AR, Peebles K, Brosenitsch T, Robinson DM, Housley GD, Funk GD (2004) P2 receptors modulate respiratory rhythm but do not contribute to central CO2 sensitivity in vitro. Respir Physiol Neurobiol 142:27-42.

Lorier AR, Huxtable AG, Robinson DM, Lipski J, Housley GD, Funk GD (2007) P2Y1 receptor modulation of the pre-Botzinger complex inspiratory rhythm generating network in vitro. J Neurosci 27:993-1005.

Lorier AR, Lipski J, Housley GD, Greer JJ, Funk GD (2008) ATP sensitivity of preBotzinger complex neurones in neonatal rat in vitro: mechanism underlying a P2 receptor-mediated increase in inspiratory frequency. J Physiol 586:1429-1446.

Mongin AA, Kimelberg HK (2005) ATP regulates anion channel-mediated organic osmolyte release from cultured rat astrocytes via multiple $\mathrm{Ca} 2+-$ sensitive mechanisms. Am J Physiol Cell Physiol 288:C204-213.

Neary JT, van Breemen C, Forster E, Norenberg LO, Norenberg MD (1988) ATP stimulates calcium influx in primary astrocyte cultures. Biochem Biophys Res Commun 157:1410-1416.

Newman EA (2003) Glial cell inhibition of neurons by release of ATP. J Neurosci 23:1659-1666.

North RA (2002) Molecular physiology of P2X receptors. Physiol Rev 82:1013-1067.

Parpura V, Basarsky TA, Liu F, Jeftinija K, Jeftinija S, Haydon PG (1994) Glutamate-mediated astrocyte-neuron signalling. Nature 369:744-747.

Porter JT, McCarthy KD (1997) Astrocytic neurotransmitter receptors in situ and in vivo. Prog Neurobiol 51:439-455.

Ruangkittisakul A, Ballanyi K (2006) Reversal by phosphodiesterase-4 blockers of in vitro apnea in the isolated brainstem-spinal cord preparation from newborn rats. Neurosci Lett 401:194-198.

Ruangkittisakul A, Schwarzacher SW, Secchia L, Poon BY, Ma Y, Funk GD, Ballanyi K (2006) High sensitivity to neuromodulator-activated signaling pathways at physiological $\left[\mathrm{K}^{+}\right]$of confocally imaged respiratory center neurons in on-line-calibrated newborn rat brainstem slices. J Neurosci 26:11870-11880 
Ruangkittisakul A, Schwarzacher SW, Secchia L, Ma Y, Bobocea N, Poon BY, Funk GD, Ballanyi K (2008) Generation of eupnea and sighs by a spatiochemically organized inspiratory network. J Neurosci 28 : 2447-2458.

Silinsky EM, Gerzanich V, Vanner SM (1992) ATP mediates excitatory synaptic transmission in mammalian neurones. Br J Pharmacol 106:762-763.

Smith JC, Ellenberger HH, Ballanyi K, Richter DW, Feldman JL (1991) PreBotzinger complex: a brainstem region that may generate respiratory rhythm in mammals. Science 254:726-729.

Too HP, Marriott DR, Wilkin GP (1994) Preprotachykinin-A and substance $\mathrm{P}$ receptor $(\mathrm{NK} 1)$ gene expression in rat astrocytes in vitro. Neurosci Lett 182:185-187.

Tooney PA, Au GG, Chahl LA (2000) Tachykinin NK1 and NK3 receptors in the prefrontal cortex of the human brain. Clin Exp Pharmacol Physiol 27:947-949.

Tsacopoulos M (2002) Metabolic signaling between neurons and glial cells: a short review. J Physiol Paris 96:283-288.

Yip J, Chahl LA (2001) Localization of NK1 and NK3 receptors in guineapig brain. Regul Pept 98:55-62.

Young JK, Dreshaj IA, Wilson CG, Martin RJ, Zaidi SI, Haxhiu MA (2005) An astrocyte toxin influences the pattern of breathing and the ventilatory response to hypercapnia in neonatal rats. Respir Physiol Neurobiol 147:19-30.

Zhang JM, Wang HK, Ye CQ, Ge W, Chen Y, Jiang ZL, Wu CP, Poo MM, Duan S (2003) ATP released by astrocytes mediates glutamatergic activity-dependent heterosynaptic suppression. Neuron 40:971-982. 